\title{
New phytochemicals from the corms of medicinally important South African Hypoxis species
}

\author{
Kokoette Bassey ${ }^{\mathrm{a}}$, Alvaro Viljoen ${ }^{\mathrm{a}, *}$, Sandra Combrinck ${ }^{\mathrm{a}}$, Young Hae Choi ${ }^{\mathrm{b}}$ \\ ${ }^{a}$ Department of Pharmaceutical Sciences, Tshwane University of Technology, Private Bag X680, Pretoria 0001, South Africa \\ ${ }^{\mathrm{b}}$ Natural Products Laboratory, Institute of Biology, Leiden University, Sylviusweg 72, 2333BE Leiden, The Netherlands
}

\section{A R T I C L E I N F O}

\section{Article history:}

Received 10 September 2014

Received in revised form 18 September 2014

Accepted 19 September 2014

Available online 1 October 2014

\section{Keywords:}

Hypoxis

Orcinal glycoside

Galpinoside

Hypoxoside

Geraniol glycoside

$\beta$-Sitosterol

High performance countercurrent

chromatography

\begin{abstract}
A B S T R A C T
Hypoxis species (Hypoxidaceae) are amongst the most widely used medicinal plants in southern Africa. Although the phytochemistry of Hypoxis hemerocallidea has been extensively investigated, little is known regarding the secondary metabolites of the other indigenous species, including Hypoxis colchicifolia and Hypoxis galpinii. Two new phenolic glycosides, 3-hydroxy-4-O- $\beta$-D-glucopyranosylbenzaldehyde and 1,5-bis(3,4-dihydroxyphenyl)-1,2-dihydroxy-4-pentyne-2-p-coumaroyl- $\beta$-D-glucopyranoside were isolated from corms of $H$. colchicifolia and $H$. galpinii, respectively. The norlignan glycosides (hypoxoside, dehydroxy hypoxoside and bis-dehydroxy hypoxoside) were isolated from $H$. colchicifolia for the first time, using high performance countercurrent chromatography and elucidated by $1 \mathrm{D}$ and 2D NMR as well as high resolution MS. In addition, geraniol glycoside and $\beta$-sitosterol, previously described in Hypoxidaceae, were isolated from the same species. The presence of hypoxoside in all three species investigated indicated that the interchangeable use of Hypoxis species by communities has some merit. Establishing the biological properties of the new constituents will provide more insight into the medicinal value of the genus.
\end{abstract}

(c) 2014 Phytochemical Society of Europe. Published by Elsevier B.V. All rights reserved.

\section{Introduction}

The genus Hypoxis represents approximately 90 species and is the largest in the family Hypoxidaceae R.Br. (Singh, 2007, 2009). Although the latest checklist of the South African Biodiversity Institute (Germishuizen et al., 2006) records more than 40 species of Hypoxis as indigenous to South Africa, Singh (2009) revised these to only 29 distinct species. She indicated that Hypoxis colchicifolia Baker is synonymous with Hypoxis latifolia, Hypoxis gilgiana, Hypoxis oligotricha and Hypoxis distachya, and incorporated Hypoxis rooperi, Hypoxis elata, Hypoxis patula and Hypoxis obconica into Hypoxis hemerocallidea Fisch. \& CAMey. Although $H$. hemerocallidea is the most sought after Hypoxis species, $H$. colchicifolia is also widely marketed throughout South Africa (Dold and Cocks, 2002). Traditionally, the corms of $H$. colchicifolia are used as a diuretic and for the treatment of psychiatric disturbances. It is also use to kill

\footnotetext{
This paper forms part of a special issue of Phytochemistry Letters dedicated to the memory of Andrew Marston (1953-2013), outstanding phytochemist who is much missed by his friends.

* Corresponding author. Tel.: +27 12 3826360; fax: +27 123826243.

E-mail address: viljoenam@tut.ac.za (A. Viljoen).
}

small vermin and is administered to cattle to cure gall sickness and redwater (bovine babesiosis) (Hutchings, 1996). The plant has cultural significance within the Zulu community and is used to prepare infusions as a cure for barrenness and impotency (Gertsner, 1939; Bryant, 1996). Extracts of $H$. hemerocallidea are used to treat a variety of diseases and disorders, including prostate hypertrophy (Bandeira et al., 2001), urinary and venereal disorders (Louw, 2002), cancer (Koduru et al., 2007) and diabetes (Erasto et al., 2005). Extracts are applied topically to relieve skin disorders such as rashes and wounds (Grierson and Afolayan, 1999) and are used for HIV/AIDS management (Manfredi and Chiodo, 1999). Infusions are taken to treat dizziness, bladder disorders and insanity (Hutchings, 1996). Not only are several of the species, including Hypoxis rigidula, $H$. hemerocallidea, Hypoxis obtusa, Hypoxis galpinii, H. colchicifolia and Hypoxis acuminata, morphologically alike (Singh, 2009), but they are all used in traditional medicine and reportedly contain similar chemical constituents (Boukes et al., 2008).

Hypoxis species are known to produce a variety of phytoglycosides, including several norlignan glycosides (Marini-Bettolo et al., 1982; Drewes et al., 1984; Galeffi et al., 1989; Sibanda et al., 1991) and phenolic glycosides (Cheng et al., 2009; Matsuo et al., 2011). Hypoxoside, a norlignan diglycoside, is the best known of these 
metabolites, since its aglycone, rooperol, is believed to play an important role in the medicinal properties of Hypoxis (Albrecht, 1996). A number of sterols, including $\beta$-sitosterol, and sterolins have also been detected in Hypoxis species (Boukes et al., 2008). However, it is well established that combinations of bioactive compounds, rather than single components, provide an important concurrent effect on multiple pharmacological targets (Pallares et al., 2012). Although it is known that H. colchicifolia and H. galpinii Baker (synonym Hypoxis stricta) produce hypoxoside (Drewes and Liebenberg, 1987), there is a lack of data regarding other secondary metabolites produced by these species. For this reason, structurally and functionally diverse compounds, produced via different metabolic pathways in the corms, should be investigated to establish whether $H$. colchicifolia and $H$. galpinii can be substituted for $H$. hemerocallidea in the market place. Many of the Hypoxis species are referred to by the same common name and are used interchangeably as traditional medicine by rural communities in South Africa. It is therefore of interest to determine if the chemical constituents of the species overlap.

In this investigation, secondary metabolites present in corms of $H$. colchicifolia and $H$. galpinii were isolated using silica gel column chromatography and high performance countercurrent chromatography (HPCCC). Silica gel separations are plagued by low yields resulting from irreversible adsorption of compounds to the stationary phase and extensive tailing (Yang and Ito, 2005). Although currently largely obsolete, countercurrent distribution (CCD) techniques were originally designed to eliminate losses associated with stationary phase effects (Akerlund, 1984). MariniBettolo et al. (1982) isolated $100 \mathrm{mg}$ of hypoxoside from $\mathrm{H}$. obtusa using CCD. However, the development of high performance countercurrent chromatography (HPCCC) led to more efficient separations, particularly for polar and water-soluble compounds. This technique involves liquid-liquid equilibrium between immiscible solvents, aided by centrifugation (Hatti-Kaul, 2000). The compounds isolated from the two Hypoxis species were identified using nuclear magnetic resonance (NMR) spectroscopy and ultraperformance liquid chromatography-mass spectrometry (UPLCMS). These compounds will be used as reference standards to establish chemotypical variations within the genus and to develop methods for quality control purposes.

\section{Results and discussion}

\subsection{Identification of isolated compounds}

Seven compounds (six from $H$. colchicifolia and one from $H$. galpinii), including two new compounds, were isolated.

$\beta$-Sitosterol (1) from the $\mathrm{CHCl}_{3}$ extract of $\mathrm{H}$. colchicifolia. The spectroscopic data of $\mathbf{1}$ are in agreement with data reported by Kamboj and Saluja (2011) for $\beta$-sitosterol. This sterol has been identified in extracts of $H$. hemerocallidea, Hypoxis stellipidis and
Hypoxis sobolifera (Boukes et al., 2008). The immune-boosting and cholesterol lowering properties of sterols, such as $\mathbf{1}$ and their use as functional food supplements are well documented (Bouic, 2001).

Geraniol glycoside (2) from $H$. colchicifolia (Table 1 ). An $R_{\mathrm{f}}$ value of 0.71 was obtained by TLC using $\mathrm{CHCl}_{3}-\mathrm{MeOH}-\mathrm{H}_{2} \mathrm{O}(70: 30: 2)$ as developing solvent. Compound $\mathbf{2}$ was previously reported from Hypoxis acuminata by Bredenkamp et al. (1989).

3-Hydroxy-4-O- $\beta$-D-glucopyranosylbenzaldehyde (orcinal glycoside) (3) from $H$. colchicifolia (Fig. 1; Table 1).

Chemical shifts obtained from the ${ }^{1} \mathrm{H}$ and ${ }^{13} \mathrm{C}$ NMR spectrum of 3 indicated the presence of an aldehyde proton ( $\delta 9.80)$, three aromatic protons $(\delta 7.21,7.39$ and 7.28) and one anomeric carbon at $\delta 101.2 \mathrm{ppm}$. The ${ }^{13} \mathrm{C}$ NMR of 3 resonated at $\delta 192.1(\mathrm{C}=0), 151.2$ (ortho-oxygenated carbon), 147.6 (phenoxy-C) and at $101.2 \mathrm{ppm}$ (anomeric carbon). Also evident from the ${ }^{13} \mathrm{C}$-ATP experiment were three quaternary carbons at $\delta 151.2,148.0,131.5$, one methylene at $\delta 61.1$ and nine methines at $\delta 192.1,123.5,115.8$, $115.1,101.2,77.7,76.4,73.6$ and $70.2 \mathrm{ppm}$, respectively. The linkages between the aldehyde, phenol and sugar moieties at C-1 and $\mathrm{C}-4$ of the phenol were determined for $\mathbf{3}$ by heteronuclear multiple-bond correlation (HMBC) (Fig. 1). This spectrum showed that the aldehyde proton $(\delta 9.87 \mathrm{ppm})$ was correlated to the phenyl $\mathrm{C}-1(\delta 131.49)$ and the glucose $\mathrm{H}-1(\delta 4.94)$ correlated to phenyl C-4 ( $\delta 151.2 \mathrm{ppm})$. The attachment of the glucose to the $\mathrm{C}-4$ of the ring was further proven from the HMBC correlation at $\mathrm{H}-\mathrm{C}(\delta 7.24-$ 147.40 ) and the COSY phenyl $\mathrm{H}-\mathrm{H}$ correlation at $\delta 7.24-7.36$. This compound is chemically related to orcinol glycoside, reported by Gupta et al. (2005) from Curculigo orchioides (Hypoxidaceae). However, the methyl group in orcinol glycoside was absent in 3; instead, a carbonyl carbon signal that resonated at $\delta 192.1$ was evident. These presences of the hydrogen on the carbonyl carbon was deduced from the heteronuclear single quantum correlation (HSQC) experiment that indicates a short-range J-coupling between $\mathrm{H}-\mathrm{C}$ at $\delta 192.1$ and its proton at $\delta 9.80$. On the basis of these diagnostic features 3 was identified as 3-hydroxy-4-O- $\beta$-Dglucopyranosylbenzaldehyde. As far as could be ascertained, this compound has not been reported before.

The presence of orcinal glycoside in $H$. colchicifolia is likely to be the result of the biosynthetic transformation of orcinol glycoside in the plant. Orcinol glycoside was found to exhibit moderate antioxidant activity against the hydroxyl radical $\left(\mathrm{IC}_{50}=1.39 \mathrm{mM}\right)$ and the superoxide anion $\left(\mathrm{IC}_{50}=2.49 \mathrm{mM}\right.$ ), when compared to the positive control, epigallocatechin gallate (EGCG; hydroxyl radical: $\mathrm{IC}_{50}=0.43$, superoxide anion: $\mathrm{IC}_{50}=0.53$ ) (Wu et al., 2005). It is a reasonable assumption that orcinal glycoside would also display good antioxidant activity.

Compounds 4, 5 and $\mathbf{6}$ were identified as hypoxoside, dehydroxy hypoxoside and bis-dehydroxy hypoxoside, respectively, using NMR, UPLC-MS data and literature values (Table 1). Although these analogues are difficult to resolve due to their structural similarities and highly polar nature, they were

Table 1

Compounds isolated from Hypoxis species with their corresponding retention times and fragmentation data as established by UPLC-MS

\begin{tabular}{|c|c|c|c|c|c|}
\hline Comp ID & Compound name & $\begin{array}{l}\text { Retention } \\
\text { time (min) }\end{array}$ & $\begin{array}{l}\text { Mass to } \\
\text { charge } \\
\text { ratio }(\mathrm{m} / \mathrm{z})\end{array}$ & MS-MS fragmentation & Reference \\
\hline 1 & $\beta$-Sitosterol & $\mathrm{N} / \mathrm{A}$ & 414.01 & $396,354,329,303,255,231,213,199,173,159,145,133,119,105,81$. & Kamboj and Saluja (2011) \\
\hline 2 & Geraniol glycoside & 7.60 & 447.16 & $\begin{array}{l}447(\mathrm{M}-\mathrm{H}), 295\left(\mathrm{M}-\mathrm{C}_{10} \mathrm{H}_{19} \mathrm{O}\right), 163\left(\mathrm{M}-\mathrm{C}_{10} \mathrm{H}_{19} \mathrm{O}-\mathrm{C}_{11} \mathrm{H}_{19} \mathrm{O}_{9}-\mathrm{C}_{5} \mathrm{H}_{9} \mathrm{O}_{4}\right) \\
155\left(\mathrm{M}-\mathrm{C}_{5} \mathrm{H}_{9} \mathrm{O}_{4}\right)\end{array}$ & Bredenkamp et al. (1989) \\
\hline 3 & Orcinal glycoside & 1.64 & 299.11 & $299\left(\mathrm{M}-\mathrm{H}^{+}\right) ; 137\left(\mathrm{C}_{7} \mathrm{H}_{5} \mathrm{O}_{3}\right)$ & New \\
\hline 4 & Hypoxoside & 4.58 & 605.11 & $641\left(\mathrm{M}+\mathrm{Cl}^{-}\right) ; 605\left(\mathrm{M}-\mathrm{H}^{+}\right) ; 443\left(\mathrm{C}_{23} \mathrm{H}_{23} \mathrm{O}_{9}\right) ; 281\left(\mathrm{C}_{17} \mathrm{H}_{12} \mathrm{O}_{4}\right)$ & Drewes et al. (1984) \\
\hline 5 & Dehydroxy hypoxoside & 4.89 & 589.11 & $625\left(\mathrm{M}+\mathrm{Cl}^{-}\right) ; 589(\mathrm{M}) ; 427\left(\mathrm{C}_{23} \mathrm{H}_{23} \mathrm{O}_{8}\right) ; 264\left(\mathrm{C}_{17} \mathrm{H}_{12} \mathrm{O}_{3}\right)$ & Laporta et al. (2007) \\
\hline 6 & bis-Dehydroxy hypoxoside & 5.20 & 609.09 & $609\left(\mathrm{M}+\mathrm{Cl}^{-}\right) ; 573(\mathrm{M}) ; 411\left(\mathrm{C}_{23} \mathrm{H}_{23} \mathrm{O}_{7}\right) ; 248\left(\mathrm{C}_{17} \mathrm{H}_{12} \mathrm{O}_{2}\right)$ & Laporta et al. (2007) \\
\hline 7 & Galpinoside & 4.27 & 623.09 & $\begin{array}{l}623\left([\mathrm{M}-\mathrm{H}) ; 461\left(\mathrm{M}-\mathrm{C}_{9} \mathrm{H}_{7} \mathrm{O}_{3}\right) ; 325\left(\mathrm{M}-\mathrm{C}_{17} \mathrm{H}_{15} \mathrm{O}\right) ; 299\left(\mathrm{C}_{15} \mathrm{H}_{17} \mathrm{O}_{8}\right) ;\right. \\
163\left(\mathrm{M}-\mathrm{C}_{23} \mathrm{H}_{25} \mathrm{O}_{10}\right) ; 160\left(\mathrm{M}-\mathrm{C}_{17} \mathrm{H}_{15} \mathrm{O}_{8}-\mathrm{C}_{9} \mathrm{H}_{7} \mathrm{O}_{3}\right)\end{array}$ & New \\
\hline
\end{tabular}




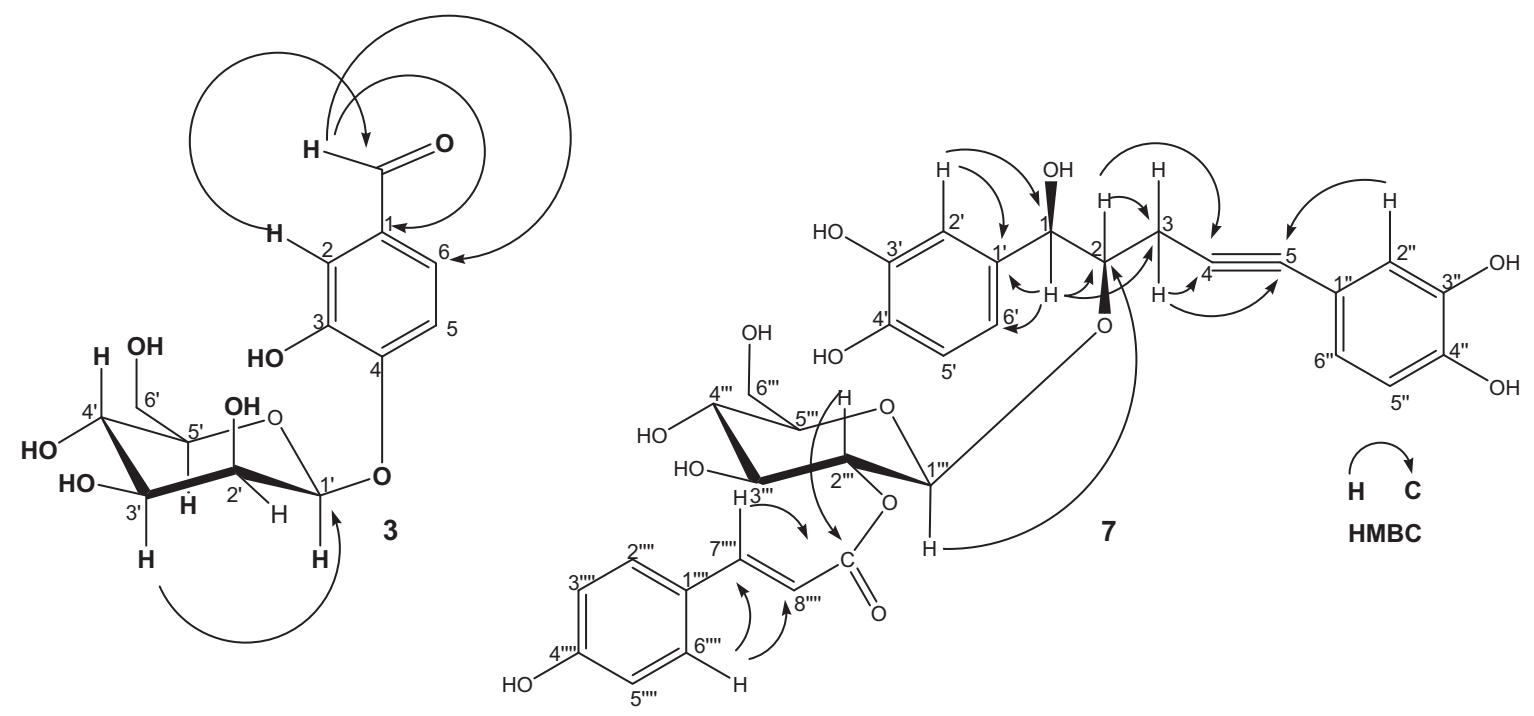

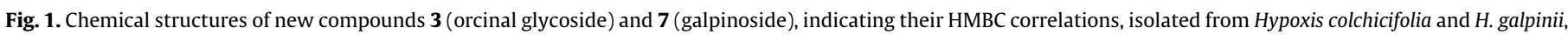
respectively.

successfully separated using HPCCC (Fig. 2). This technique is popular for the separation of polar extracts that are often difficult to separate using classical methods such as column chromatography (Marston and Hostettmann, 2006). The high performance countercurrent chromatograph (HPCCC) used in this study can achieve a g-level (the ratio of the column radius, $r$, to rotor radius, $R$ ) of 240 , as opposed to the $55-80 \mathrm{~g}$ generated in high speed countercurrent chromatography (HSCCC), implying short cycle times and faster flow rates, comparable to those of preparative scale high performance liquid chromatography (www.dynamicextractions.com/technology/countercurrent-chromatography-history. html).

The chromatographic (Table 1) and spectroscopic data obtained for the norlignan glycosides, hypoxoside (4), dehydroxy hypoxoside (5) and bis-dehydroxy hypoxoside (6) corresponded to those reported in the literature (Marini-Bettolo et al., 1982; Drewes et al., 1984; Laporta et al., 2007). Hypoxoside was first isolated from $H$. obtusa by Marini-Bettolo et al. (1982) and later by Drewes et al. (1984) from $H$. rooperi (synonym $H$. hemerocallidea). Rooperol, the aglycone of hypoxoside, is known to have valuable anticancer and

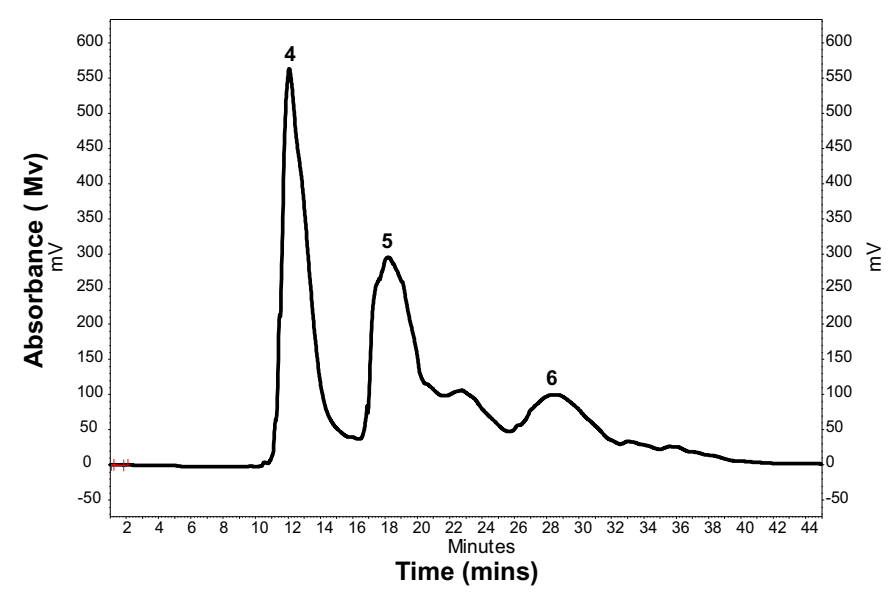

Fig. 2. High performance countercurrent chromatogram obtained by normal phase mode for a mixture containing hypoxoside $\left(4 ; R_{\mathrm{t}}\right.$ 11.5-14.5 min), dehydroxy hypoxoside $\left(5 ; R_{\mathrm{t}} 18.3-21.8 \mathrm{~min}\right)$ and bis-dehydroxy hypoxoside $\left(\mathbf{6} ; R_{\mathrm{t}} 25.5-\right.$ $33.0 \mathrm{~min})$. Solvent: $\mathrm{CHCl}_{3}-n-\mathrm{BuOH}-\mathrm{MeOH}-\mathrm{H}_{2} \mathrm{O}(7.5: 10: 7.5: 25)$. UV $\lambda=260 \mathrm{~nm}$. antimutagenic properties (Albrecht et al., 1995). Whereas the biological activities of hypoxoside are well documented, those of the derivatives ( 5 and $\mathbf{6}$ ) are unknown.

Compound 7, a dark brown amorphous solid was isolated from the acetone extract of the aerial parts of $H$. galpinii. M.p. 165$167{ }^{\circ} \mathrm{C} ; \alpha_{\mathrm{D}}{ }^{20}+0.025$ (c $\left.0.1 \mathrm{MeOH}\right)$. $\mathrm{UV}_{\mathrm{MeOH}} \lambda_{\max } 256$ and $299 \mathrm{~nm}$. The IR absorptions at 3523, 3010, 2550-2108, 2263 and $1660 \mathrm{~cm}^{-1}$ indicated the presence of hydroxyl, olefinic or phenyl, ketone, alkyne functional groups. The negative HRESIMS of $\mathbf{7}$ displayed a molecular adduct ion peak $[\mathrm{M}-\mathrm{H}]^{+}$at $m / z 623.1837$, suggesting the molecular formula $\mathrm{C}_{32} \mathrm{H}_{31} \mathrm{O}_{13}$ (Table 1 ). The ${ }^{1} \mathrm{H}$ NMR spectrum of 7 displayed signals for six aromatic protons in two ABX systems, which might result from catechol-like moieties, both being correlated by the ${ }^{1} \mathrm{H}-{ }^{1} \mathrm{H}-\mathrm{COSY}$ spectrum, and two aliphatic signals (Table 2). Both sets of catechol-moieties, one at $\delta 6.84(1 \mathrm{H}, \mathrm{br} \mathrm{s})$ and $\delta 6.72(2 \mathrm{H}, \mathrm{brd}, J=1.2 \mathrm{~Hz})$, and the other at $\delta 6.79(1 \mathrm{H}, \mathrm{d}, J=2.0 \mathrm{~Hz})$, $\delta 6.68(1 \mathrm{H}, \mathrm{dd}, J=8.5,2.0 \mathrm{~Hz})$ and $\delta 6.59(1 \mathrm{H}, \mathrm{d}, J=8.5 \mathrm{~Hz})$ indicate a nyasicol-type norlignan, together with four aliphatic protons at $\delta$ $4.52(1 \mathrm{H}, \mathrm{d}, J=8.5 \mathrm{~Hz}), \delta 3.93(1 \mathrm{H}, \mathrm{m}), \delta 2.40(1 \mathrm{H}, \mathrm{dd}, J=17.5$, $2.6 \mathrm{~Hz})$ and $\delta 2.10(1 \mathrm{H}, \mathrm{dd}, J=17.5,6.1 \mathrm{~Hz})$, while the acetylene moiety was confirmed by bands in the IR spectrum at 2550$2108 \mathrm{~cm}^{-1}$ (Marini-Bettolo et al., 1982). One of the sets of catechol moieties was conjugated, with an acetylene moiety confirmed by HMBC correlations of $\mathrm{H}-2^{\prime \prime}$ at $\delta 6.79(1 \mathrm{H}, \mathrm{d}, J=2.0 \mathrm{~Hz})$ and $\mathrm{H}-6^{\prime \prime}$ at $\delta$ $6.68(1 \mathrm{H}, \mathrm{dd}, J=8.5,2.0 \mathrm{~Hz})$ to $\mathrm{C}-5$ at $\delta 83.6 . \mathrm{H}-2$ at $\delta 3.93(1 \mathrm{H}, \mathrm{m})$. In addition, $\mathrm{H}-3$ at $\delta 2.40(1 \mathrm{H}, \mathrm{dd}, J=17.5,2.6 \mathrm{~Hz})$ and $\delta 2.10(1 \mathrm{H}$, dd, $J=17.5,6.1 \mathrm{~Hz})$ were also correlated to $\mathrm{C}-4$ at $\delta 84.1$ in the HMBC spectrum (Fig. 1).

A sugar moiety was detected by the presence of an anomeric proton at $\delta 4.91(1 \mathrm{H}, \mathrm{d}, J=8.5 \mathrm{~Hz})$ and $\mathrm{H}-2^{\prime \prime \prime}$ at $\delta 4.95(1 \mathrm{H}$, dd, $J=9.9 \mathrm{~Hz}, 8.5 \mathrm{~Hz}$ ). This coupling constant for an anomeric proton and the downfield shift of $\mathrm{H}-2$ of the $\beta$-glucose indicated that $p$ coumaric acid is conjugated to the $\mathrm{C}-2$ position (Marini-Bettolo, $1991)$. Also, the chemical shift of $C-1^{\prime \prime \prime}$ at $\delta 101.1$ confirmed the $\beta$ configuration of the $O$-glycosidic linkage. Typical protons of $p$ coumaric acid were detected in the ${ }^{1} \mathrm{H}$ NMR spectrum at $\delta 7.14(\mathrm{H}-$ $2^{\prime \prime \prime}$ and $\mathrm{H}-6^{\prime \prime \prime}$, seemingly $\left.\mathrm{d}, J=8.2 \mathrm{~Hz}\right), \delta 6.70\left(\mathrm{H}-3^{\prime \prime \prime}\right.$ and $\mathrm{H}-5^{\prime \prime \prime}$, seemingly d, $J=8.2 \mathrm{~Hz}), \delta 7.53\left(\mathrm{H}-7^{\prime \prime \prime} \mathrm{d}, J=16.0 \mathrm{~Hz}\right)$, and $\delta 6.21(\mathrm{H}-$ $7^{\prime \prime \prime} \mathrm{d}, J=16.0 \mathrm{~Hz}$ ). In the HMBC spectrum (Fig. 1 ), there were correlations between $\mathrm{H}-1^{\prime \prime \prime}$ at $\delta 4.92(1 \mathrm{H}, \mathrm{d}, J=8.0 \mathrm{~Hz})$ and $\mathrm{C}-2$ at $\delta$ 83.5 , and $\mathrm{H}-2^{\prime \prime \prime} \delta 4.95(1 \mathrm{H}, \mathrm{dd}, J=8.0 \mathrm{~Hz}, 8.0 \mathrm{~Hz})$ and $\mathrm{C}=\mathrm{O}$ of $p-$ coumaric acid at $\delta 168.8$. On the basis of these MS and NMR data 
Table 2

${ }^{1} \mathrm{H}$ and ${ }^{13} \mathrm{C}$ NMR data $(\delta / \mathrm{ppm})$ a for compound 7 (galpinoside) in $\mathrm{CH} 3 \mathrm{OH}-d_{4}$.

\begin{tabular}{llr}
\hline Position & Compound 7 & \\
\cline { 2 - 3 } & $\delta_{\mathrm{H}}(\mathrm{J} / \mathrm{Hz})$ & $\delta_{\mathrm{C}}$ \\
\hline 1 & $4.52(\mathrm{~d}, 8.5)$ & 76.6 \\
2 & $3.93(\mathrm{~m})$ & 83.5 \\
3 & $2.40(\mathrm{dd}, 17.5,2.6)$ & 22.9 \\
& $2.10(\mathrm{dd}, 17.5,6.1)$ & \\
4 & - & 84.1 \\
5 & - & 83.6 \\
$1^{\prime}$ & - & 133.0 \\
$2^{\prime}$ & $6.84(\mathrm{br} \mathrm{s})$ & 115.4 \\
$3^{\prime}$ & - & 146.4 \\
$4^{\prime}$ & - & $146.3^{\mathrm{b}}$ \\
$5^{\prime}$ & $6.72(\mathrm{br} \mathrm{d}, 2.0)$ & 119.5 \\
$6^{\prime}$ & $6.72(\mathrm{br} \mathrm{d}, 2.0)$ & 120.3 \\
$1^{\prime \prime}$ & - & 116.3 \\
$2^{\prime \prime}$ & $6.79(\mathrm{~d}, 2.0)$ & 116.6 \\
$3^{\prime \prime}$ & - & 146.8 \\
$4^{\prime \prime}$ & - & 146.1 \\
$5^{\prime \prime}$ & $6.59(\mathrm{~d}, 8.5)$ & 119.4 \\
$6^{\prime \prime}$ & $6.68(\mathrm{dd}, 8.5,2.0)$ & 125.0 \\
$1^{\prime \prime \prime}$ & $4.91(\mathrm{~d}, 8.5)$ & 101.1 \\
$2^{\prime \prime \prime}$ & $4.95(\mathrm{dd}, 9.9,8.5$ & 76.7 \\
$3^{\prime \prime \prime}$ & $3.64(\mathrm{~m})$ & 74.3 \\
$4^{\prime \prime \prime}$ & $3.46(\mathrm{~m})$ & 75.5 \\
$5^{\prime \prime \prime}$ & $3.49(\mathrm{~m})$ & 76.3 \\
$6^{\prime \prime \prime}$ & $3.74(\mathrm{~m})$ & 62.0 \\
$1^{\prime \prime \prime \prime}$ & - & 131.1 \\
$2^{\prime \prime \prime \prime}$ & $7.14(\mathrm{~d}, 8.2)$ & 127.4 \\
$3^{\prime \prime \prime \prime}$ & $6.70(\mathrm{~d}, 8.2)$ & 116.8 \\
$4^{\prime \prime \prime \prime}$ & - & 161.2 \\
$5^{\prime \prime \prime \prime}$ & $6.70(\mathrm{~d}, 8.2)$ & 116.8 \\
$6^{\prime \prime \prime \prime}$ & $7.14(\mathrm{~d}, 8.2)$ & 127.4 \\
$7^{\prime \prime \prime \prime}$ & $7.53(\mathrm{~d}, 16.0)$ & 146.6 \\
$8^{\prime \prime \prime \prime}$ & $6.21(\mathrm{~d}, 16.0)$ & 115.3 \\
$\mathrm{C}=\mathrm{O}$ & - & 168.8 \\
\hline & & \\
\hline & & \\
\hline
\end{tabular}

the chemical structure of 7 was elucidated to be 1,5-bis(3,4dihydroxyphenyl)-1,2-dihydroxy-4-pentyne-2-p-coumaroyl- $\beta$-Dglucopyranoside, referred to as galpinoside.

This compound has been reported by Marini-Bettolo (1991) from Hypoxis interjecta and Hypoxis multiceps. However, the compound was an enzyme hydrolyzed product obtained from interjectin, which has one additional glucose attached to the C-4" position of 7. There are two chiral centres in the compound, $\mathrm{C}-1$ and $\mathrm{C}-2$. In the case of 1,5-bis(3,4-dihydroxyphenyl)-1,2-dihydroxy-4-pentyne-2- $\beta$-D-glucopyranoside (nyasicoside), the absolute configuration of $\mathrm{C}-1$ and $\mathrm{C}-2$ were assigned as the $R$ and $S$ configuration, respectively (Chifudera et al., 1994). However, later, Chang et al. (1999) revised the configuration of C-2 as $R$ by $\mathrm{CD}$ experiments. In order to confirm the configurations in this study, the relative configuration of $\mathrm{C}-1$ and $\mathrm{C}-2$, threo $(1 R, 2 R)$ or erythro $(1 R, 2 S)$ was determined by ${ }^{1} \mathrm{H}$ NMR spectroscopy. Although enantiomers cannot be distinguished by NMR spectroscopy, diastereomers would be expected to be differentiated once one of the absolute configurations is known, for example $R$ for $\mathrm{C}-1$.

Coupling constants of $\mathrm{H}-1$ of $(1 R, 2 R)-(-)$-pseudoephedrine and $(1 R, 2 S)-(-)$-ephedrine were compared to each other. The coupling constant of $\mathrm{H}-1$ of pseudoephedrine is $9.1 \mathrm{~Hz}$ and for ephedrine was determined as $3.2 \mathrm{~Hz}$. Thus, the relative configuration of 7 was thought to be the threo form, probably the $1 R, 2 R$ configuration.

All the ${ }^{1} \mathrm{H}$ and ${ }^{13} \mathrm{C}$ NMR assignments are listed in Table 2. Some doubtful assignments of phenolic protons in previous research (Chifudera et al., 1994), for example B-ring protons were clearly resolved with the help of ${ }^{1} \mathrm{H}-{ }^{1} \mathrm{H}-\mathrm{COSY}, \mathrm{HSQC}$ and HMBC.

\subsection{Ultra performance liquid chromatography analysis}

The purities of the isolated compounds were established to be in excess of 95\% using UPLC-MS. These compounds then served as reference standards for their identification in extracts using this technique. The traditional use of Hypoxis mainly involves the preparation of aqueous extracts of the fresh corms. However, in this study, methanol $(\mathrm{MeOH})$ was used to prepare polar extracts from the corms of the three Hypoxis species, since TLC indicated similar fingerprints for aqueous and $\mathrm{MeOH}$ extracts. Comparison of the UPLC-MS chromatograms obtained (Fig. 3) revealed corresponding peaks at retention times $4.58 \mathrm{~min}(\mathrm{~m} / \mathrm{z} 605.11)$ and $4.89 \mathrm{~min}(\mathrm{~m} / \mathrm{z} 589.11)$, which were identified as hypoxoside and dehydroxy hypoxoside, respectively. The prominent peak at $5.20 \mathrm{~min}(\mathrm{~m} / \mathrm{z} 609.09)$ in the chromatogram of $H$. colchicifolia corresponded to bis-dehydroxy hypoxoside. The corresponding peaks were also evident in the chromatograms of the other two species. Laporta et al. (2007) previously reported the presence of these three compounds in $H$. rooperi (synonym $H$. hemerocallidea). Peak areas for hypoxoside using the PDA detector were similar for $H$. hemerocallidea (47919 AU), $H$. colchicifolia (45621 AU) and $H$. galpinii (44732 AU). Significantly higher levels of dehydroxy hypoxoside (34198 AU) and bis-dehydroxy hypoxoside (18671 AU) were present in the corms of $H$. colchocifolia than in the other two species. However, $H$. hemerocallidea contained similar amounts of these metabolites (dehydroxy hypoxoside: 15014 AU, bis-dehydroxy hypoxoside: $4558 \mathrm{AU}$ ) to H. galpinii (dehydroxy hypoxoside: 14990 AU, bis-dehydroxy hypoxoside: $4467 \mathrm{AU}$ ).

A peak in the chromatogram of $H$. colchicifolia (Fig. 3) at $1.14 \mathrm{~min}(\mathrm{~m} / \mathrm{z} 377.02)$ was identified as sucrose, while that occurring at $5.67(\mathrm{~m} / z$ 611.10) in all three species was not identified. However, the peaks at $4.27 \mathrm{~min}(\mathrm{~m} / z$ 623.09) and $7.60 \mathrm{~min}(\mathrm{~m} / \mathrm{z} 447.16)$, common to all three species, represented galpinoside and geraniol glycoside, respectively. The peak, specific to $H$. colchicifolia, with retention time $4.03 \mathrm{~min}(\mathrm{~m} / \mathrm{z} 643.11)$, could not be identified.

In conclusion, two new compounds, orcinal glycoside and galpinoside, were isolated from South African Hypoxis species, adding to the list of secondary metabolites from the genus. In addition, dehydroxy hypoxoside, bis-dehydroxy hypoxoside, geraniol glycoside and $\beta$-sitosterol are herein reported for the first time as metabolites of $H$. colchicifolia. The presence of the phenolic glycosides in Hypoxis is of clinical importance, because such compounds comprising C6-linkers-C6 have value in mitigating osteoporosis (Wang et al., 2012) and may act as efficient inhibitors of fibrils that are responsible for conditions such as Alzheimer's disease (Riviere et al., 2007). Further investigations of the biological properties of the new compounds isolated in this study will shed light on the medicinal value of the genus. Chemical profiling of other Hypoxis species, using the isolated compounds as standards, will reveal interchangeable species for medicinal use.

\section{Experimental}

\subsection{Plant material}

Specimens of $H$. colchicifolia and $H$. galpinii were available from previous research and voucher specimens (HC024 and HG008, respectively) were subsequently identified by Prof. Braam van Wyk from the University of Pretoria, prior to their deposition at the Department of Pharmaceutical Sciences, Tshwane University of Technology, Pretoria, South Africa. The tap roots were removed from the fresh corms, which were separated from the plant. After washing, the corms were chopped into small pieces and oven dried at $30{ }^{\circ} \mathrm{C}$ for $36 \mathrm{~h}$ prior to extraction. The resulting dried plant material was then pulverized using a Retsch ${ }^{\circledR}$ MM 400 ball milling 

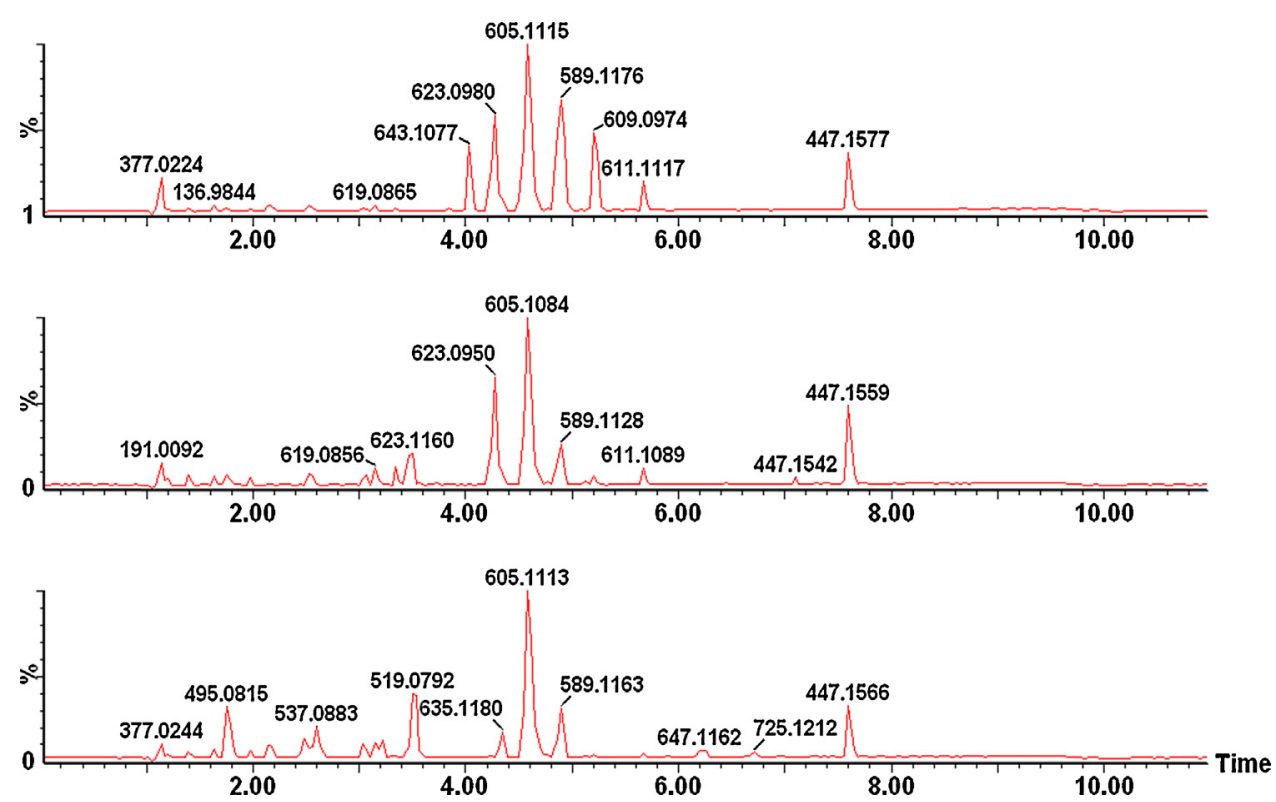

Fig. 3. Chromatograms (UPLC-MS) of the methanol extracts of corms of (A) Hypoxis colchicifolia, (B) Hypoxis galpinii and (C) Hypoxis hemerocallidea.

machine (Monitoring and Control Pty Ltd., Haans, Germany) at a frequency of $30.0 \mathrm{~Hz}$ for $120 \mathrm{~s}$ to yield fine brown powders. These powders were sieved using a $500 \mu \mathrm{m}$ mesh size (Endcotts Filters Ltd., London, UK) to ensure consistency of particle size.

\subsection{Extraction of secondary metabolites}

All solvents, purchased from Merck (Pty) Ltd. (Johannesburg, Gauteng, South Africa), were of analytical reagent grade. Powdered H. colchicifolia (427 g) was divided into three equal portions, which were individually treated until the mass became manageable for combination. Each portion of the plant material was extracted with $3 \mathrm{ml} \times 250 \mathrm{ml} \mathrm{CHCl}$ by sonication at $30{ }^{\circ} \mathrm{C}$ for $30 \mathrm{~min}$ and filtered (No. 4, Whatman, Buckinghamshire, UK). The resulting filtrates were combined and evaporated under reduced pressure at $40{ }^{\circ} \mathrm{C}$ using a rotary evaporator (Büchi Labortechnik R200, Flawil, Switzerland). Thereafter, the remaining portions of plant material were each extracted with methanol $(\mathrm{MeOH} ; 3 \mathrm{ml} \times 250 \mathrm{ml})$, which after combination and evaporation of the solvent, resulted in a residue with a mass of $116 \mathrm{~g}$.

\subsection{Isolation of compounds}

Extracts were sonicated (Bandelin Electronic, Berlin, Germany) in an appropriate solvent before application to columns for separation. For vacuum liquid chromatography (VLC), a vacuum pump (Sartorius Stedim, Goettingen, Germany) was attached to a glass column (Labotec (Pty) Ltd., Midrand, South Africa), packed with silica gel (Kieselgel 60, Machery-Nagel, Neumann-Neander, Düren, Germany), to increase the flow rate of the mobile phase through the column.

H. colchicifolia: The $\mathrm{CHCl}_{3}$ extract ( $3.08 \mathrm{~g}$ ) was batch eluted by VLC using $\mathrm{CHCl}_{3}$ and $\mathrm{MeOH}$. The $\mathrm{CHCl}_{3}$ eluate was further purified by CC; petroleum ether as eluent yielded 1 (190 mg). A small amount of $2(16.5 \mathrm{mg})$ was isolated from the $\mathrm{MeOH}$ batch using $\mathrm{CHCl}_{3}$-acetone (90:10) for elution.

The initial $\mathrm{MeOH}$ extract was passed through a VLC column, which was eluted sequentially with EtOAc and EtOH. Since the EtOH fraction contained all the compounds of interest, this fraction (35.0 g) was further purified on a second VLC column by sequential batch elution using $\mathrm{CHCl}_{3}$ and EtOH. The EtOH fraction (9.35 g), containing the target metabolites, was subsequently purified by conventional column chromatography (CC) using $\mathrm{CHCl}_{3}-\mathrm{MeOH}-$ $\mathrm{H}_{2} \mathrm{O}$ (70:30:2) as eluent. Following TLC analysis, the fractions were combined as follows: A $\left(0.57 \mathrm{~g} ; R_{\mathrm{f}} 0.72-0.70\right)$, B $\left(1.50 \mathrm{~g} ; R_{\mathrm{f}} 0.70-\right.$ $0.65), \mathrm{C}\left(2.34 \mathrm{~g} ; R_{\mathrm{f}} 0.50-0.48\right)$ and D (5.12 g; $\left.R_{\mathrm{f}} 0.45-0.20\right)$. Compound 2 (167 mg) was obtained from Fraction A upon rechromatography on silica gel using $\mathrm{CHCl}_{3}$-acetone (90:10) as eluent, thus bringing the total amount of 2 to $184 \mathrm{mg}$. Fraction B was further chromatographed on a Sephadex ${ }^{\circledR}$ LH-20 (SigmaAldrich, Johannesburg, Gauteng, South Africa) column with $\mathrm{CHCl}_{3}-$ $\mathrm{MeOH}-\mathrm{H}_{2} \mathrm{O}$ (70:30:2) as mobile phase to yield 3 (12.5 mg). Fraction D applied to silica gel, using EtOAc-MeOH (90:10) as the mobile phase, afforded pure 4 ( $800 \mathrm{mg}$ ) and a mixture of 4,5 and 6 $(126 \mathrm{mg}$ ). The mixture of $\mathbf{4 , 5}$ and $\mathbf{6}$ was later purified by a single HPCCC separation.

H. galpinii: The plant was extracted with EtOAc, followed by acetone. The residue $(5.70 \mathrm{~g})$ resulting from the acetone extract, containing the target compounds, was further purified by silica gel $\mathrm{CC}$ using $\mathrm{CHCl}_{3}-\mathrm{MeOH}-\mathrm{H}_{2} \mathrm{O}$ (70:30:2). The resulting fractions, containing the target compound, were combined $(1.02 \mathrm{~g})$ and applied to a second silica gel column using the same mobile phase to yield 7 (310 $\mathrm{mg}$ ).

\subsection{High performance countercurrent chromatography}

Preparative HPCCC was achieved using a hydrodynamic multilayer coil-planet g-type centrifuge (Spectrum, Dynamic Extractions Ltd., Slough, UK), fitted with two semi-preparative columns (175 ml total volume, $1.6 \mathrm{~mm}$ i.d.) connected in series. Solvent was pumped with an HPLC quaternary gradient pump (Model Q-grad, Scientific System Inc., State College, PA 16803, USA). The HPCCC was equipped with a reticulating chiller to maintain a constant column temperature of $30-32{ }^{\circ} \mathrm{C}$. Compounds in the eluent, collected by a fraction collector (Model FC203B, Gilson, Middleton, USA), were detected using a UV-VIS detector (Sapphire 600, EACOM, Prague, Czech Republic), fitted with a preparative flow cell, at $260 \mathrm{~nm}$. Data acquisition was accomplished by EZChrom software data and HPCCC runs were monitored by Agilent Interface 35900E.

After evaluating a variety of solvent mixtures using the method described by Marston and Hostettmann (2006), the solvent 
combination of $\mathrm{CHCl}_{3}-n-\mathrm{BuOH}-\mathrm{MeOH}-\mathrm{H}_{2} \mathrm{O}$ (7.5:10:7.5:25) was selected for HPCCC separation of the compounds. The mixture of 4 , 5 and 6 (126 mg) was dissolved in $3 \mathrm{ml}$ of upper phase (UP) and $3 \mathrm{ml}$ of lower phase (LP) and filtered through a $0.20 \mu \mathrm{m}$ filter (Bonna-Agela Technologies; Stargate Scientific, Wilgeheuwel, South Africa). Normal phase semi-preparative mode was used by filling the column with $65 \mathrm{ml}$ of the stationary phase (LP). The coils were rotated at $1600 \mathrm{rpm}$, where after the mobile phase (UP) was pumped at $6.0 \mathrm{ml} / \mathrm{min}$, until dynamic equilibrium was reached at $50 \mathrm{ml}$. At this stage, the pre-loaded sample was injected into the column and a run time of $60 \mathrm{~min}$, comprising $45 \mathrm{~min}$ for elution and 15 min for extrusion, was permitted. Compounds 4 (40 mg), 5 (15 mg) and $\mathbf{6}$ (10 mg) were isolated as cream coloured fluffy powders at retention times of $11.5-14.5 \mathrm{~min}, 18.3-21.8 \mathrm{~min}$ and 25.5-33.0 min, respectively (Fig. 2). A total mass of $840 \mathrm{mg}$ of 4 was derived from the polar extracts of all three species.

\subsection{Nuclear magnetic resonance spectroscopy}

Spectra were recorded on a Bruker 600 Avance II NMR (Bruker, Bellerica, MA, USA) at $600 \mathrm{MHz}$ for ${ }^{1} \mathrm{H}$ NMR and $150 \mathrm{MHz}$ for ${ }^{13} \mathrm{C}$ NMR. Two dimensional (2D) NMR experiments were performed using standard Bruker microprograms. Measurements were made in $\mathrm{CD}_{3} \mathrm{OD}$ and the solvent signals were used for calibration. The purities and identities of isolated compounds were confirmed by comparing ${ }^{1} \mathrm{H}$ and ${ }^{13} \mathrm{C}$ NMR signals, UPLC-MS data, IR signals and UV absorption wavelengths with literature values (Table 1 ).

3-Hydroxy-4-O- $\beta$-D-glucopyranosylbenzaldehyde (orcinal glycoside) (3) A new compound isolated from $H$. colchicifolia (Fig. 1; Table 1). Colourless semi-solid oil. $\mathrm{UV}_{\mathrm{MeOH}} \lambda_{\max } 225,270$ and $309 \mathrm{~nm}$. IR (KBr) v $3525(-\mathrm{OH}), 1725(\mathrm{C}=\mathrm{O})$ and $3012(\mathrm{Ph}-\mathrm{H}) \mathrm{cm}^{-1}$. ${ }^{1} \mathrm{H}$ NMR $\left(600 \mathrm{MHz}, \mathrm{CD}_{3} \mathrm{OD}\right) \delta 9.80(\mathrm{H}, \mathrm{s}, \mathrm{CH}=\mathrm{O}), 7.21(\mathrm{H}, \mathrm{s}, \mathrm{Ph}-2)$, 7.39 (H, d, $J=8 \mathrm{~Hz}, \mathrm{Ph}-5), 7.28$ (H, d, $J=8 \mathrm{~Hz}, \mathrm{Ph}-6), 4.94$ (H, d, $J=8 \mathrm{~Hz}$, glc- 1$), 3.50(\mathrm{H}, \mathrm{t}, J=8.5 \mathrm{~Hz}$, glc- 3$), 3.48(\mathrm{H}, \mathrm{t}, J=7.5 \mathrm{~Hz}$, glc2), $3.45(\mathrm{H}, \mathrm{t}, J=8.5 \mathrm{~Hz}$, glc-4), $3.47(\mathrm{H}, \mathrm{m}$, glc-5), $3.42(2 \mathrm{H}, \mathrm{m}$, glc-6). ${ }^{13} \mathrm{C} \mathrm{NMR}\left(\mathrm{CD}_{3} \mathrm{OD}\right) \delta 192.14,151.16,147.99,131.49,123.49,115.76$, $115.13,101.17,77.71,76.40,73.62,70.17$ and 61.08 ppm. HRESIMS (negative ion mode) $\mathrm{m} / z \quad 300.24$ (Calculated for $\mathrm{C}_{13} \mathrm{H}_{16} \mathrm{O}_{8}$ $300.08[\mathrm{M}+1])$. HRESIMS fragmentation pattern reported in Table 1 . An $R_{\mathrm{f}}$ value of 0.65 was obtained by TLC using $\mathrm{CHCl}_{3}-$ $\mathrm{MeOH}-\mathrm{H}_{2} \mathrm{O}$ (70:30:2) as developing solvent.

\subsection{Ultra high performance liquid chromatography analysis}

Methanol extracts of $H$. colchicifolia, $H$. hemerocallidea and $H$. galpinii were introduced by full-loop injection $(1.0 \mu \mathrm{l})$ into a UPLC (Waters Acquity chromatographic system; Waters, Milford, MA, USA), equipped with a photo diode array (PDA) detector. This detector was used to optimize the separations during the initial analyses. Extracts and pure compounds were separated on an Aquity UPLC BEH $\mathrm{C}_{18}$ column $(150 \mathrm{~mm} \times 2.1 \mathrm{~mm}$, i.d., $1.7 \mu \mathrm{m}$ particle size; Waters) maintained at $40{ }^{\circ} \mathrm{C}$. The mobile phase consisted of $0.1 \%$ aqueous formic acid (Solvent A) and HPLC grade (Merck $^{\mathrm{TM}}$, Germany) acetonitrile (Solvent B), at a flow rate of $0.3 \mathrm{ml} / \mathrm{min}$. Gradient elution was applied as follow: $85 \% \mathrm{~A}: 15 \% \mathrm{~B}-$ $65 \% \mathrm{~A}: 35 \% \mathrm{~B}$ in $7 \mathrm{~min}$, changed to $50 \% \mathrm{~A}: 50 \% \mathrm{~B}$ in 1 min (held for $2.5 \mathrm{~min}$ ), before returning to the initial ratio in $0.5 \mathrm{~min}$ (a total run time of $11 \mathrm{~min}$ ). Data were managed by Markerlynx 4.1 chromatographic software.

The UPLC system was interfaced with a combination time-offlight/quadrupole Xevo $\mathrm{G}_{2} \mathrm{QT}$ mass spectrometer (Waters, USA). For the UPLC-MS analyses, the same column, elution gradient and flow rate were used as before. Although both positive and negative ion modes were applied, the results obtained indicated that higher sensitivities and more information were obtained in the negative mode. The mass spectrometer was therefore operated in negative ion electrospray mode using nitrogen as the desolvation gas at a flow rate of $600 \mathrm{~L} / \mathrm{h}$. A desolvation temperature of $350{ }^{\circ} \mathrm{C}$ and a source temperature of $100{ }^{\circ} \mathrm{C}$ were used. The capillary and cone voltages were set to 2500 and $40 \mathrm{~V}$, respectively. Data were collected in the range $m / z 100-1200$.

\section{Acknowledgements}

The authors thank the Faculty of Science, Tshwane University of Technology of South Africa for financial assistance towards this study and the National Research Foundation for their contribution towards the equipment used.

\section{References}

Akerlund, H.-E., 1984. An apparatus for counter-current distribution in a centrifugal field. J. Biochem. Biophys. Methods 9, 133-141.

Albrecht, C.F., 1996. Hypoxoside: a putative prodrug for the treatment of malignancies, HIV infection and inflammatory conditions. In: Proceedings First International IOCD-Symposium, 25. Victoria Falls, Zimbabwe, 2-1995, pp. 302-307

Albrecht, C.F., Kruger, P.B., Smith, B.J., Freestone, M., Gouws, L., Miller, R., Van Jaarsveld, P.P., 1995. The pharmacokinetic behaviour of hypoxoside taken orally by patients with lung cancer in a phase I trial. S. Afr. Med. J. 85, 861-865.

Bandeira, S.O., Gasper, F., Pagula, F.P., 2001. African ethnobotany and healthcare: emphasis on Mozambique. Pharm. Biol. 39, 70-73.

Boukes, J.G., van de Venter, M., Oosthuizen, V., 2008. Quantitative and qualitative analysis of sterols/sterolins and hypoxoside contents of three Hypoxis (African potato) spp. Afr. J. Biotechnol. 7, 1624-1629.

Bouic, P.J.D., 2001. The role of phytosterols and phytosterolins in immune modulation: a review of the past 10 years. Curr. Opin. Clin. Nutr. Metab. Care 4, 471-475.

Bredenkamp, M.W., Drewes, S.E., Wentler, G.L., 1989. A geraniol glycoside from Hypoxis acuminata. Phytochemistry 28, 263-265.

Bryant, A.T., 1996. Zulu Medicine and Medicine-men. C. Struik, Cape Town.

Chang, W.L., Chen, C.H., Lee, S.L., 1999. Three new constituents from Curculigo capitulata and revision of C-2 stereochemistry in nyasicoside. J. Nat. Prod. 62, 734-739.

Chifudera, K., Palazzino, G., Messana, I., Li, P., Galeffi, C., Cannarasa, G., 1994 Norlignan glucoside from Curculigo recurvate. Phytochemistry 35, 1343-1348.

Cheng, Z.Q., Yang, D., Liu, Y.Q., Hu, J.M., Jiang, H.Z., Wang, P.C., Li, N., Zhuo, J., Zhao, Y.X., 2009. Two new phenolic glycosides from Hypoxis aurea Lour. Bull. Korean Chem. Soc. 30, 2446-2448.

Dold, A.P., Cocks, M.L., 2002. The trade in medicinal plants in the Eastern Cape Province, South Africa. S. Afr. J. Sci. 98, 589-597.

Drewes, S.E., Hall, H.J., Learmonth, R.A., Upfold, U.J., 1984. Isolation of hypoxoside from Hypoxis rooperi and synthesis of [E]-1,5-bis[3,4-dimethoxyphenyl] pent-4en-1-yne. Phytochemistry 23, 1313-1316.

Drewes, S.E., Liebenberg, R.W., 1987. Extraction of Plants of the Family Hypoxidaceae for the Treatment of Cancer. Patent 0092226. Courier Press, Leamington Spa., England, Europe.

Erasto, P., Adebola, P.O., Grierson, D.S., Afolayan, A.J., 2005. An ethnobotanical study of plants used for the treatment of diabetes in the Eastern Cape Province, South Africa. Afr. J. Biotechnol. 4, 1458-1460.

Galeffi, C., Multari, G., De Vicente, Y., Messana, I., Nicoletti, M., Marini-Bettolo, G., 1989. Two new glucosides from Hypoxis obtusa: obtuside A and obtuside B. Planta Med. 55, 318-320.

Germishuizen, G., Meyer, N.L., Steenkamp, Y., Keith, M., 2006. A Checklist of South African Plants. Southern Africa Botanical Diversity Network Report No. 41. SABONET, Pretoria.

Gertsner, J., 1939. A preliminary checklist of Zulu names of plants with short notes. Bantu Stud. 13, 307-326.

Grierson, D.S., Afolayan, A.J., 1999. An ethnobotanical study of plants used for the treatment of wounds in the Eastern Cape, South Africa. J. Ethnopharmacol. 67, 327-332.

Gupta, M., Achari, B., Pal, B.C., 2005. Glucoside from Curculigo orchioides. Phytochemistry 66, 659-663.

Hatti-Kaul, R., 2000. Aqueous Two Phase Systems: Methods and Protocols. Methods in Biotechnology, vol. 11. Humana Press Inc., Totowa, New Jersey.

Hutchings, A., 1996. Zulu Medicinal Plants: An Inventory. University of Natal Press, Pietermaritzburg.

Kamboj, A., Saluja, A.K., 2011. Isolation of stigmasterol and $\beta$-sitosterol from the petroleum ether extract of aerial parts of Ageratum conyzoides (Asteraceae). Int. J. Pharm. Pharm. Sci. 3, 94-96.

Koduru, S. Grierson, D.S., Afolayan, AJ. 2007. Ethnobotanical information of medicinal plants used for treatment of cancer in the Eastern Cape Province, South Africa. Curr. Sci. 92, 906-908.

Laporta, O., Perez-Fons, L., Mallavia, R., Caturla, N., 2007. Isolation, characterization and antioxidant capacity assessment of the bioactive compounds derived from Hypoxis rooperi corm extract (African potato). Food Chem. 101, 1425-1437. 
Louw, I., 2002. A pilot study of the clinical effects of a mixture of $\beta$-sitosterol and $\beta$ sitosterolglucoside in active rheumatoid arthritis (RA). Am. J. Clin. Nutr. 75, 351S (Abstract 40).

Manfredi, R., Chiodo, F., 1999. Non-conventional treatments and HIV disease: determining factors and consequences. Med. Maladies Infect. 29, 125-129.

Marini-Bettolo, G.B., 1991. Research on African medicinal plants. XXVII. Interjectin, a derivative of nyasicoside from Hypoxis interjecta and Hypoxis multiceps. Tetrahedron 47, 6717-6724.

Marini-Bettolo, G.B., Nicoletti, P.M., Galeffi, C., Messana, I., 1982. Hypoxoside a new glycoside with uncommon structure from Hypoxis obtusa Busch. Tetrahedron 38, 1683-1687.

Marston, A., Hostettmann, K., 2006. Developments in the application of countercurrent chromatography to plant analysis. J. Chromatogr. A 1112, 181-194.

Matsuo, Y., Tachikawa, F., Mimaki, Y., 2011. Phenolic glycosides from Rhodohypoxis baurii. J. Nat. Med. 65, 224-228.

Pallares, V., Calay, D., Cedo, L., Castell-Auvi, A., Raes, M., Pinent, M., Ardevol, A., Arola, L., Blay, M., 2012. Additive, antagonistic and synergistic effects of procyanidins and polyunsaturated fatty acid over inflammation in RAW 264.7 macrophages activated by lipopolysaccharide. Nutrition 28, 447-457.
Riviere, C., Richard, T., Vitrac, X., Merillon,J.-M., Valls, J., Monti,J.-P., 2007. New phenols active on $\beta$-amyloid aggregation. Bioorg. Biomed. Chem. Lett. 18, 828-831.

Sibanda, S., Nyandat, E., Galeffi, C., Nicoletti, M., 1991. The co-occurrence of hypoxoside and nyasoside in Hypoxis obtusa Burch-complex. Rev. Latinoamer Quim. 22, 37-38.

Singh, Y., 2007. Hypoxis (Hypoxidaceae) in southern Africa: taxonomic notes. S. Afr. J. Bot. 73, 360-365.

Singh, Y., 2009. Systematics of Hypoxis (Hypoxidaceae) in Southern Africa. (Ph.D. thesis)University of Pretoria, Pretoria, South Africa.

Wang, Y., Zhao, L., Wang, Y., Xu, J., Nie, Y., Guo, Y., Tong, Y., Qin, L., Zhang, Q., 2012. Curculigoside isolated from Curculigo orchiodes prevents hydrogen peroxideinduced dysfunction and oxidative damage in calvarial osteoblasts. Acta Biochim. Biophys. Sin. 44, 431-441.

Wu, Q., Fu, D.-X., Hou, A.-J., Lei, G.-Q., Liu, Z.-J., Cheng, J.-K., Zhou, T.-S., 2005. Antioxidant phenols and phenolic glycosides from Curculigo orchioides. Chem. Pharm. Bull. 53, 106.

Yang, F., Ito, Y., 2005. Chapter 11: Alkaloids: Separation by countercurrent chromatography. In: Cazes, J. (Ed.), Encyclopedia of Chromatography. 2nd ed. CRC Press, New York, pp. 46-81. 